\title{
Right Crisis Management in the Era of Pandemic Covid 19, Keeping Work Motivation and Opportunities of Survival from the Crisis
}

\author{
Pangestu Widodo*, Muhardi Muhardi \\ Management Faculty \\ Universitas Islam Bandung \\ Bandung, Indonesia \\ *ipang.widodo@gmail.com
}

(Field Study in Padjadjaran Clinic, Sumedang and Garut)

\begin{abstract}
The impact of the crisis, as experienced by the world's population in 2020 due to the Covid 19 pandemic, concerns two aspects of the company, namely health and finance and even socio-culture1. First, the impact directly hit the health sector with many casualties and secondly in the economic sector it was also affected by the number of companies that closed down and the number of mass layoffs. This study is to find out how company management motivates employees to survive in the company in the face of Covid 19. Because at the beginning of the Pandemic, employee motivation had decreased. The research was conducted at the Padjadjaran Clinic Jatinangor Sumedang and Garut. Through Forum Group Discussion and Interview with Clinic management and employee personnel. The results showed that the active role and presence of management in the midst of employees fostered and increased them to fight together. This can be seen from the company's improved performance 3-6 months after the PSBB (Large-Scale Social Restriction).
\end{abstract}

Keywords-crisis management, work motivation, pandemic, covid 19, Padjadjaran Clinic

\section{INTRODUCTION}

A recession is a condition of a country's economic growth minus two consecutive quarters. As a result of the COVID-19 pandemic around the world, in Indonesia it was carried out PSBB (Large-Scale Social Restrictions), starting from March to May 2020. For approximately three months. PSBB resulted in a recession in the economic sector. The period leading up to the recession is called a crisis period where in addition to panic occurring due to conditions of economic uncertainty, national health conditions are not good. A pandemic is a multinational disease epidemic that attacks all over the world with large casualties and brings about changes in health and economics globally throughout the world.

In June -2020 - August because the government was also struggling to get the country out of the threshold of recession, the government relaxed the PSBB, this phase is called the New
Habit Adaptation (AKB) phase. There has been a change in attitudes and behaviour in society. In Indonesia, economic growth in the second quarter was minus $5.2 \%$, meaning that in the 3rd quarter of 2020, Indonesia's minus growth was officially entering the brink of recession [1]. The recession is marked by mass unemployment, the economy is paralyzed and people's purchasing power decreases. At the time this research was made we are still in the third quarter. The government is trying to provide an economic stimulus to prevent minus growth in the 3rd quarter of 2020.

The economic impact was felt in March 2020 when the PSBB was carried out, Large-Scale Social Restrictions where individual physical contact was not allowed. Suddenly all the joints of life changed. The world was gripped by panic. Several companies were forced to lay off their employees. At this time, careful management is needed to first survive the Covid 19 pandemic. Second, survive economically.

However, as a believer, under any circumstances, work is still a nature of life. believe that every life there must be a test from God including the provision of faith. What is more, if believed and lived with optimism, it will be a way for improving the quality of life and life. There is always a balance in everything. There is a wisdom in every problem. In every crisis there must be danger but there must also be opportunities, lessons and lessons learned. It remains how we respond to this. With positive thoughts or with negative ones.

\section{RESEARCH METHODS}

The research method used is descriptive qualitative with interview techniques and holding Forum Group Discussions (FGD) on central and regional clinical management [2]. This method was chosen to help researchers explore problems during the Covid 19 pandemic and how employees at the Padjadjaran Jatinangor Clinic in Sumedang and Garut faced various problems that might arise during the pandemic. This 
research uses two data. Primary data was taken from interviews and group discussion forums as well as secondary data from weekly and monthly data and reports made during the pandemic period.

\section{DISCUSSION}

The impact of the crisis is divided into two, personal impacts and organizational (community) impacts. Personal impact, is about how to deal with personal emotional problems due to changes in lifestyle, way of working, mental attitudes, balance between personal and family life, managing stress, and changing to a personal comfort zone into an uncomfortable zone. Whereas the impact as an organization is, questions about the impact of a pandemic at work, company response, towards growth profit or decline, progress or survival, rearranging organizational strategies, strengthening organizational values based on organizational culture and management. How companies react to the crisis [3].

As illustrated in Figure 1 below:

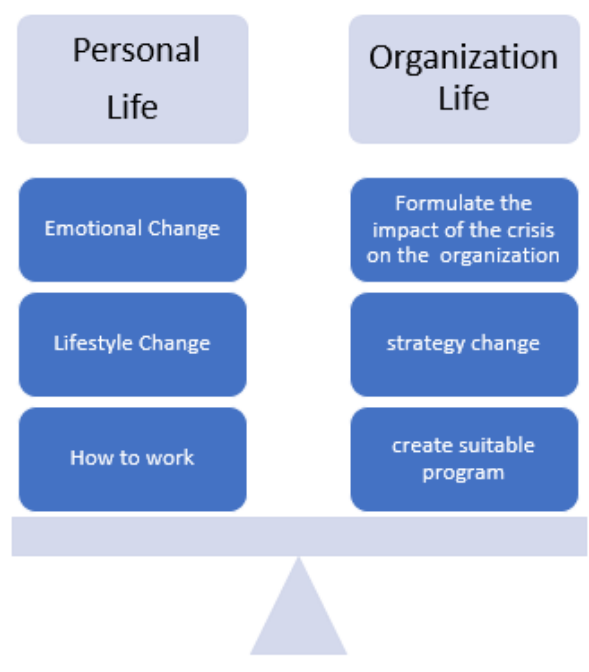

Fig. 1. The impact of the crisis on individuals and organizations.

To determine employee behaviour in a crisis era, three types of crisis management should also be identified, namely [3]:

- Fear Zone (as individuals or organizations accept this condition, there is no denial, and try to manage this by rearranging the organizational strategy) This is also called the response period.

- Learning Zone (is a time for every individual and organization to heal, become

- stronger and more resilient) This is also called the recovery stage.

Growth Zone (a period of growth towards a new normal or the new term is an adaptation to new habits), both personal and organizational to create a new formula, redesign, manipulate in facing the New Normal Adaptation or New Normal [4]. This is the thrive stage.

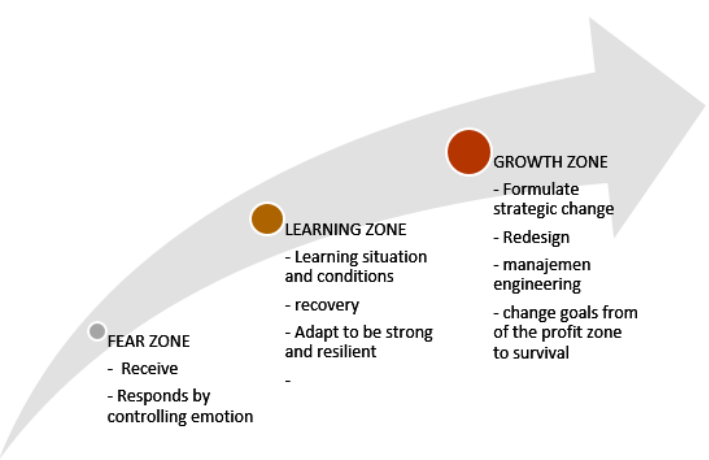

Fig. 2. Three stages of crisis management.

In an era of crisis, aside from resignation and tawakal, optimism must still be put forward. If you realize that a crisis is God's test, then every servant should be patient in living life. Some patterns of life have clearly occurred and changed.

Changes that occurred during the PSBB and AKB era were as follows: People are advised to always wear masks, keep their distance, wash their hands with detergent, stay away from crowds, and there are new online habits in the world of work that reduce physical contact and direct contact with the community [5].

What a leader needs when a crisis occurs is not planned handling but how to prevent overreaction to the crisis and how to carry the organization into the future. all management must also communicate effectively to maintain transparency and notify them regularly [6].

The things done by Padjadjaran Clinic in Sumedang and Garut to maintain employee motivation [7-10] are:

- Close ranks between management first and change the Clinic's policy strategy from initially growing profit to survival mode on. Because one of the functions of management is to provide rational directions for the sake of a goal [1].

- Provide a newsletter to employees on what is happening and how the company is dealing with it.

- Pay more attention to employees in the form of clear appeals and steps to employees and to remain positive.

- Prioritizing togetherness between management and employees.

- Follow government calls to implement Health When in office protocols and to protect their workplace as a source of income.

- Providing PPE assistance for Personal Protection Equipment (masks) to employees. Safe and healthy working conditions as the basis for decent work [11]. 
- Reducing working hours in line with decreasing income needs.

- Employees are given the understanding that this is a long term strategy. In a crisis, the important thing is to be able to get out of the crisis by surviving.

- Provide information on economic stimulus to employees and their families provided by the government, through pre-employment cards, salary subsidies, and other government programs.

- Maintain intense and periodic communication between management and employees by continuing to hold coordination meetings.

- Provide information on company developments regularly. This will maintain employee trust in the company in facing and through the crisis [6].

- Remind each other and cooperate and work hand in hand in overcoming difficulties.

In the first 3 months of the implementation of the PSBB, there was a lot of anxiety and panic among employees, but with a spirit of togetherness between management and employees. The leadership also gave advice and encouraged. That all are together in going through and facing this crisis. The clinic remains open. With service programs tailored to the needs of the community. Of course, in that month, patient visits decreased drastically. From the results of periodic evaluations, the affected income has decreased by around 15-\% - $20 \%$. However, on the other hand, the health sector is one that is lightly affected. Technically, the WFH (Work from Home) recommendation will reduce operational costs. The reduction in service hours was adjusted for decreased visits. System shifting is enforced. The clinic management, who are mostly doctors, also go down the mountain of practice in anticipation of some contract doctors who do not want to carry out their duties and choose to stay at home. The Health Protocol is strictly enforced, the distribution of PPE (Personal Protection Equipment) to employees is subject to a minimum of masks. On the good side, clinics, including health facilities that are not much exposed to Covid 19, are different from hospitals. At that stage, patient visit reports and clinic income are monitored continuously on a weekly basis. This makes it easier for management to make financial decisions. The clinic is no longer chasing profit but prioritizes the continuity of services and how to survive during a pandemic. Meetings are still held mainly through online tools to maintain the continuity of the managerial role. Circular letters via email and WA are routinely sent to employees to maintain employee motivation. In order to stay enthusiastic at work and productive both at work and at home.

In 4-6 months after PSBB or after AKB (New Habit Adaptation), it seems that employees are getting used to undergoing new normal conditions [4]. Situations and conditions that are completely new and different from before. With the opening of the PSBB, it seems that clinic visits have increased. But at the same time the risk of Covid 19 is also getting bigger. This means that people who are exposed are also getting bigger. From the covid team, even at that time in Indonesia there were 19 to 3000 cases of positive covid cases per day. This is a serious concern for management. Strict Health Protocol. prohibition to stay away from the crowd. Always wear a mask. After work immediately take a shower and change clothes are always reminded. Employees who are found to have contact with the sufferer or are exposed in the community are immediately sent home for 14 days. The procedure for checking the clinic swab test at Padjadjaran Sumedang and Garut follows the schedule of the local government. The maintenance of this strict Health protocol procedure is also carried out by appeals to their respective families because once someone is found positive for Covid 19 it will have an impact on closing the clinic by the local Health Office. This is avoided because the economic aspect of employees depends on it.

Padjadjaran Clinic implements strict rules regarding PDCA management (Plan Do Check Action) which initially reports every month to weekly. By making reports, evaluating quickly and continuously helps management in making the right decisions [12].

In months 4-6, in terms of revenue and clinic performance began to show an increasing graph. It still fluctuates but there has been improvement from the previous month. This makes employee morale and motivation increase. Moreover, it is added with the existence of a salary subsidy from the government for employees who are paid less than 5 million rupiahs. It contributes to personal economic recovery for clinic employees and their families.

\section{CONCLUSION}

The Padjadjaran Clinic in Sumedang and Garut implemented management strategies in the crisis era, managed the stages of fear, learning, and were in progress in the growing era. What employees need is the attention and presence of management together to motivate management and employees. So that togetherness grows at Padjadjaran Clinic. Indeed, the crisis era has not ended, but at least from the results of reports and interviews, several aspects of motivation and performance have improved.

Management continues to carry out analysis and evaluation regularly and continuously, working on opportunities that can still be done, working on survival patterns, working on health protocols. Also open up information and opportunities for all possibilities for learning and for growth. The Padjadjaran Sumedang and Garut clinics also apply the principles of congregation in facing the crisis era, giving mutual advice in patience and kindness. That the crisis is a test from Allah who God willing will bring to strength and glory.

\section{REFERENCES}

[1] Indonesian Statistics Agency, Statistic Official Gazette, 2020 
[2] S. Sugiyono, Metode penelitian kualitatif. Bandung: Alfabeta, 2013.

[3] N. Nurhidayati, Crisis Management. Lecture materials combined postgraduate Unisula and Unisba, 2020.

[4] H. Ginting, Behavior Change in Response Against the Covid Outbreak 19. Himpsi.or.id, 2020.

[5] A. Hendarta, Review of Professional Hospital Management. Material college, MM Unisba, 2020.

[6] G. D'Auria and A. De Smet, Leadership in a crisis: Responding to the coronavirus outbreak and future challenges, 2020.

[7] Ibn Ahmad, Crisis Management: Leadership Within facing the Covid 19 Crisis Situation, 2020.
[8] A. Kadirya, Crisis Management Analysis, scientific papers, upi.ac.id, 2012.

[9] M.K. Gultekin, Management in Crisis, Check up in crisis, Ways out of crisis, 2002.

[10] M.W. Seeger, T.L. Sellnow and R.R. Ulmer, "Communication, organization, and crisis," Annals of the International Communication Association, vol. 21, no. 1, pp. 231-276, 1998.

[11] In Facing the Pandemic: Ensuring Safety and Health at Work, International Labor Organization, 2020.

[12] P.D.C.A. Deswara, Zoom the webinar GEMS Association West Java Clinic, 2020. 